\title{
FIELD GAMMA SPECTROMETRY, MONTE CARLO SIMULATIONS AND POTENTIAL OF NON-INVASIVE MEASUREMENTS
}

\author{
GUILLAUME GUÉRIN and NORBERT MERCIER \\ Institut de Recherche sur les Archéomatériaux, UMR 5060 CNRS - Université de Bordeaux, \\ Centre de Recherche en Physique Appliquée à l'Archéologie (CRP2A), Maison de l'archéologie, \\ 33607 Pessac cedex, France
}

Received 5 November 2010

Accepted 2 November 2011

\begin{abstract}
The determination of gamma dose rates is of prior importance in the field of luminescence dating methods. In situ measurements are usually performed by the insertion of dosimeters or a portable gamma spectrometer cell in sediments. In this paper, Monte-Carlo simulations using the GEANT4 toolkit allow the development of a new technique of in-situ gamma dose rate evaluations: a spectrometer cell is placed on the surface of sediments under excavation to acquire successive spectra as sediments are removed by excavations. The principle of this non-invasive technique is outlined and its potential is discussed, especially in the case of environments in which radioelements are heterogeneously distributed. For such cases, a simple method to reconstruct gamma dose rate values with surface measurements using an attenuator is discussed, and an estimation of errors is given for two simple cases. This technique appears to be applicable, but still needs experimental validation.
\end{abstract}

Keywords: luminescence, dose rate, Monte-Carlo simulations, non-invasive measurements.

\section{INTRODUCTION}

Determining an age with luminescence dating methods requires knowledge of two physical units: the paleodose (Gy) and the dose rate $\left(G y \cdot \mathrm{a}^{-1}\right)$. The latter can be divided into the cosmic radiation contribution and the one resulting from the radioelements present in the object to be dated and its environment. This radioactivity consists of several components, namely alpha, beta and gamma radiations. If in the case of sediment grains dating, gamma radiation will contribute approximately $30 \%$ to the total dose rate, this component may go up to $80 \%$ in the case of archaeological stone artifacts (flint, quartzite, etc.). Precise ages are therefore dependent on a good knowledge of the gamma dose rate received by the object when buried, and this parameter is particularly difficult to determine in sites where heterogeneous environments result in high spatial variability of this physical quantity (e. g. Aitken, 1985; Aitken et al., 1985; Sanderson and Placido, 1985; Mercier et al., 1995; Brennan et al., 1997). Actually, one should make in that case a measurement of the gamma dose rate at the exact location where the sample comes from (by inserting a dosimeter or a portable gamma spectrometer). However, especially in the case of dating rocks (burnt artefacts) or teeth from archaeological sites, since their location is unknown before the excavation, the gamma dose rate is estimated from dosimetric data collected some distance from the piece, or after removal of material within the range of gamma radiation during the excavation. In heterogeneous sites this can potentially lead to a loss of accuracy.

Corresponding author: G. Guérin

e-mail: gguerin@u-bordeaux3.fr 
The aim of this paper is first to outline a new method for gamma radioactivity measurements of soils and test its feasibility. This non-invasive method will not solve the problem of equivalence between the measured dose rates and the dose rates really received by the objects to be dated; however it can help to reduce the potential errors by providing a set of gamma dose rate values allowing the reconstruction of the spatial variations of this quantity; this is the second scope of the paper. These developments follow requests from archaeologists who expressed their wish to avoid damaging archaeological remains when performing gamma dose rate measurements.

Due to the complexity of the problem, the approach developed here is based on Monte-Carlo simulations performed with the GEANT4 toolkit (Agostinelli et al., 2003; Allison et al., 2006), designed at the CERN (Geneva), whose use as a dosimetric tool involving gamma and $\mathrm{X}$ rays has already been demonstrated (e. g. Guimarães et al., 2008). The advantage of such simulations is that a number of parameters can be separately tuned, which would otherwise be experimentally difficult to achieve. In the field of luminescence dating techniques, Monte Carlo simulations have already been performed to overcome the lack of experimental data for a number of situations (Fain et al., 1985; Brennan et al., 1997; Nathan et al., 2003; Aznar et al., 2003; Nathan and Mauz, 2008). Such simulation techniques have also been undertaken for in-situ environmental gamma spectrometry studies (Bailiff and Slim, 2008; Allyson and Sanderson, 1998; 2001).

The gamma dose rate determination at the surface of sediments will be described in the simple case of homogeneous sediments (section 2) and then, the dose rate reconstruction will be treated in the case where the radioelements contents vary with height (section 3 ).

\section{GAMMA SPECTROMETRY SIMULATIONS}

\section{Gamma dose rate determination from surface meas- urements}

In order to derive dose rates from spectra recorded with a portable gamma spectrometer inserted in sediments, the two most common techniques are the 'window technique' and the 'threshold technique' that was first described for a semi-infinite geometry by Løvborg and Kirkegaard (1974), followed by investigations with gamma spectrometers inserted in radioactive media (Murray et al., 1978; Liritzis and Galloway, 1980; Løvborg et al., 1979; Mercier and Falguères, 2007). Sanderson and Placido (1985) studied variations in the count rate recorded above a threshold by a $\mathrm{NaI}(\mathrm{Tl})$ spectrometer as a function of depth in Scottish vitrified forts. It has been shown that the threshold technique provides more precise results in a shorter amount of time (see Miallier et al., 2009). More precisely, thus far the 'energy threshold technique' seems the most efficient solution (Guérin and Mercier, 2011). This technique consists of converting the energy deposition rate above threshold - which is the sum of the products of count-rate by corresponding channel energy for each channel above a lower threshold - in dose rate and is a variant of the Spectral Dose Index (SDI) approach proposed by Bargholz and Korsbech (1997) and Bucher et al. (2008), in which the count-rates are multiplied by the channel numbers (before energy calibration of the spectrometer). Simulated spectra recorded by a $\mathrm{LaBr}_{3}$ cell placed on the surface of calcareous sediment in which the radioactivity is homogeneously distributed have been obtained with a specifically designed GEANT4 code. The compositions of this sediment as well as the others simulated in this paper are the same as in Guérin and Mercier (2011). For all the simulations discussed in the following, the cut-off has been set to $1 \mathrm{~mm}$ for the tracking of particles, which means that particles whose range is below $1 \mathrm{~mm}$ are not tracked; in such cases energy deposition is considered local.

The simulated setup for this section is shown in Fig. 1a where the cell is simply placed on the surface of the sediment, in the air, and Fig. 2 shows the corresponding spectra, presented in the form of cumulative energy recorded above each channel (equivalent to the SDI approach). For these simulations gamma rays were homogeneously emitted in a semi-sphere of radius $70 \mathrm{~cm}$ just underneath the spectrometer cell, in the sedimentary medium. Each spectrum corresponds to one radioactivity source, i.e. thorium or uranium decay chains and potassium. Notice that the primary emission spectra have been

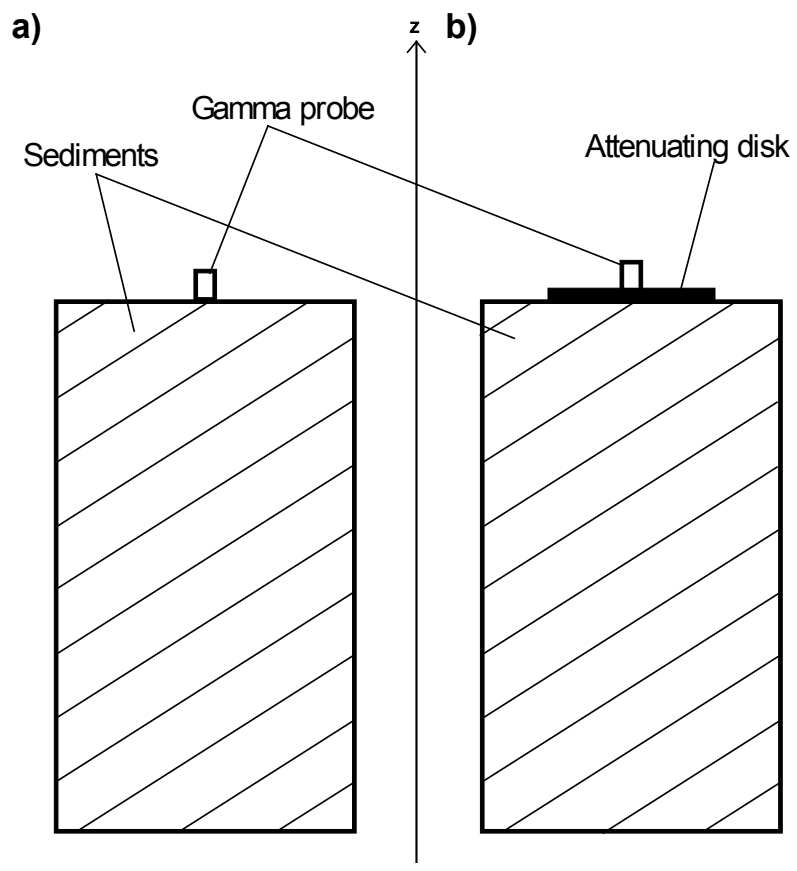

Fig. 1. Simulated setup. The crystal cell of a gamma probe is placed on top of sediments. a) The cell is directly placed on top of the sediments. b) An attenuating disk is placed between the sediments and the detecting cell. 


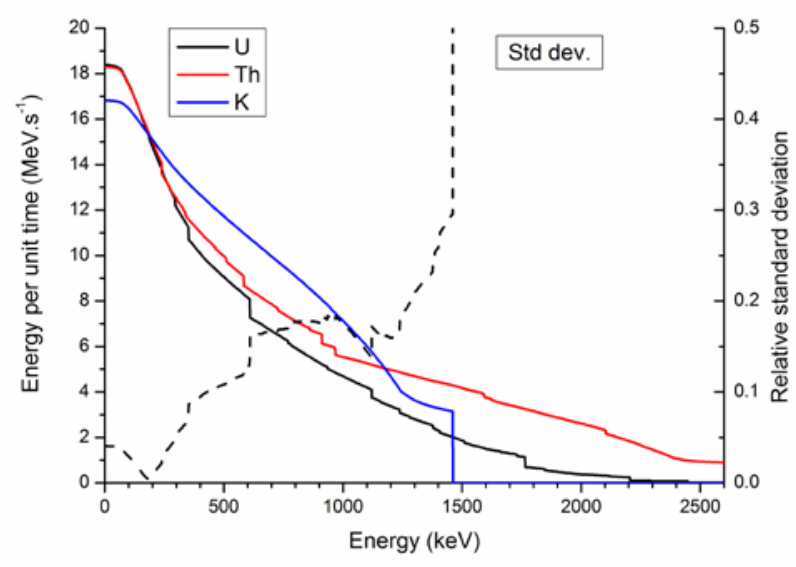

Fig. 2. Simulated cumulative energies recorded by a 1.5 inch $\times 1.5$ inch $\mathrm{LaBr}_{3}$ detector placed on the surface of infinite calcareous homogeneous sediment. Each spectrum has been normalized to a $1 \mathrm{~Gy} \cdot \mathrm{ka}^{-1}$ dose-rate. The relative standard deviation between the three cumulative energy lines reaches a minimum (0.04\%) at around $180 \mathrm{keV}$.

derived from nuclear data available on the National $\mathrm{Nu}-$ clear Data Center website ${ }^{1}$ and can be found in the electronic version of the paper by Guérin and Mercier (2011). The spectra have been normalized to match a $1 \mathrm{~Gy} \cdot \mathrm{ka}^{-1}$ dose rate. As can be seen, the three spectra are close to each other around $180 \mathrm{keV}$, which is emphasized by the relative standard deviation between the three curves. In other words, the energy deposited per second above 180 $\mathrm{keV}$ (hereafter referred to as the threshold value) does not depend on the origin of gamma rays. For this calcareous sediment, $1 \mathrm{~Gy} \cdot \mathrm{ka}^{-1}$ corresponds to $15.4 \pm 0.1 \mathrm{MeV} \cdot \mathrm{s}^{-1}$ deposited above threshold. The influence of the nature of sediments has also been tested using numerical simulations with the GEANT4 code and results are given in Table 1, indicating for each gamma source the energy deposition rate recorded above threshold. It appears that, for the sediments tested here, the energy deposition rate

Table 1. Energy deposition rate above threshold $\left(\mathrm{MeV}^{-1} \mathrm{~s}^{-1}\right.$ in a $\mathrm{LaBr}_{3}$ cell for the different radioelements found in soils and for different types of sediments. Data are normalized to a $1 \mathrm{~Gy} \cdot \mathrm{ka}^{-1}$ dose-rate and corre-

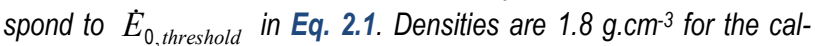
careous and siliceous sediments, $2.6 \mathrm{~g} \cdot \mathrm{cm}^{-3}$ for the lava and $1.6 \mathrm{~g} \cdot \mathrm{cm}^{-3}$ for the organic rich sediment. Uncertainties correspond to one standard deviation calculated on a series of 20 independent simulation runs.

\begin{tabular}{|c|c|c|c|}
\hline Sediment composition & $\mathrm{U}$ & Th & $\mathrm{K}$ \\
\hline Calcareous & 15.40 .2 & 15.50 .3 & 15.40 .2 \\
\hline Siliceous & 15.50 .2 & 15.60 .3 & 15.40 .2 \\
\hline Basaltic lava & 15.50 .2 & 15.90 .3 & 15.70 .2 \\
\hline Organic rich & 15.40 .2 & 15.50 .3 & 15.40 .2 \\
\hline Average & 15.4 & 15.6 & 15.5 \\
\hline Standard deviation & 0.1 & 0.2 & 0.1 \\
\hline
\end{tabular}

above threshold is very little dependent on the nature of the soils - tested sediments are a calcareous soil, a siliceous one, an organic-rich, low density sediment and a high density basaltic lava. In other words this energy deposition rate can be converted into gamma dose rate, regardless of the radiochemical composition and nature of the sedimentary environment. For that matter a simple proportionality rule would be used:

$$
\dot{D}\left(G y \cdot k a^{-1}\right)=\frac{\dot{E}_{\text {threshold }}\left(\mathrm{MeV} \cdot \mathrm{s}^{-1}\right)}{\dot{E}_{0, \text { threshold }}\left(\mathrm{MeV} \cdot \mathrm{s}^{-1}\right)}
$$

where $\dot{D}$ is the dose rate of the measured sediment, $\dot{E}_{\text {threshold }}$ is the energy deposition rate above threshold and $\dot{E}_{0, \text { threshold }}$ is the same rate for sediment in which the dose rate is $1 \mathrm{~Gy} \cdot \mathrm{ka}^{-1}$.

\section{The issue of parasitic signals}

In the case of archaeological excavations, it is very common to preserve portions of the sites for further research. This results in a number of exposed sections close to the measurements points - i.e. on top of sediments under excavation - which may induce a significant parasitic signal in the spectrometer. To overcome this problem, a lead shield placed around the cell was considered first (for similar approaches see ICRU, 1994). If one wishes to get rid of at least $95 \%$ of the parasite signal, the lead shield should be at least $4 \mathrm{~cm}$ thick. If one imagines a cylindrical sheathing wrapped around the detecting cell, its mass would reach approximately $20 \mathrm{~kg}$, which for practical reasons is unsatisfactory - archaeological remains might be damaged.

Another solution consists of a combination of two series of measurements performed at the same location: in the first the detector would simply be placed on top of the sediments, while in the second an attenuating disk would be placed between the cell and the sediments; in this latter case, only the signal emitted by the measured surface would be affected (see Fig. 1b). Consequently the difference between the two spectra, taken at the same location, would be free of parasite signal. The question remains to determine an attenuating disk that would satisfy the following conditions: a) the signal emitted by the measured surface must be attenuated in a way that makes it exploitable, in the sense that the threshold technique can still be applied to compute a reliable dose rate value and $b$ ) the signal must be affected enough for a difference between the two series of measurements to be significant.

To compute a dose rate from the difference between the two energy deposition rates (Eq. 2.1) then becomes:

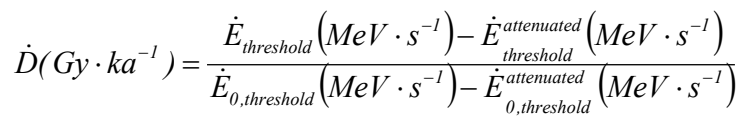

\footnotetext{
${ }^{1}$ www.nndc.bnl.gov
} 
where $\quad \dot{E}_{\text {threshold }}^{\text {attenuated }}\left(\mathrm{MeV} \cdot \mathrm{s}^{-1}\right)$ and $\dot{E}_{0, \text { threshold }}^{\text {attenuated }}\left(\mathrm{MeV} \cdot \mathrm{s}^{-1}\right)$ correspond respectively to $\dot{E}_{\text {threshold }}$ and $\dot{E}_{0, \text { threshold }}$ when the crystal cell is placed on top of the attenuating disk.

To determine the optimal disk, we first tested different materials: lead, brass, aluminum and polymethyl methacrylate.

Table 2 summarizes the results for the different simulated options. For this series of simulations, the radius of the attenuating disks was arbitrarily chosen to be equal to $15 \mathrm{~cm}$. The choice of attenuator is then driven by the precision on the dose rate computed using the difference in energy deposition rate (see Eq. 2.2); since the potassium has an average primary energy of gamma rays higher $(1461 \mathrm{keV})$ than the uranium $(537 \mathrm{keV})$ and thorium $(615 \mathrm{keV})$ decay chains, a high atomic number attenuating material is less effective for potassium than for the other two radioactive sources. This induces a loss in precision when applying the threshold technique. Polymethyl methacrylate was selected and since the precision is the same for the two tested thicknesses ( 2 and $4 \mathrm{~cm}$ ), it was decided to work with a thickness of $4 \mathrm{~cm}$ : it gives a larger difference in energy deposition rate, and thus improves the accuracy of the subtraction. The second step was to determine the adapted radius of the disk. Fig. 3 shows the results of numerical simulations performed with GEANT4: the energy deposition rate above threshold is shown for a $1.5 \times 1.5$ inches $\mathrm{LaBr}_{3}$ crystal placed on top of a disk made of polymethyl methacrylate (cf. Fig. 1b), as a function of the disk radius. The simulated sediment is the same calcareous sediment as for Fig. 2. A radius of $20 \mathrm{~cm}$ gives an attenuation of $91 \%$ of the maximum difference achievable with the chosen thickness and has been used for the simulations presented hereafter. The choice of this radius may be discussed, for instance a value of $30 \mathrm{~cm}$ would also be acceptable ( $98 \%$ of attenuation). However, to make this technique easily applicable, in-situ, over a significant portion of excavated surfaces, it is important to work with a disk as small as possible, hence the choice of $20 \mathrm{~cm}$ for the disk radius in the simulations hereafter. Fig. 4 shows the spectra corresponding to gamma irradiations from potassium, the uranium and thorium chains simulated for such an attenuating disk on the same sediment as for Fig. 2. Here again, the threshold is located at $180 \mathrm{keV}$ and $1 \mathrm{~Gy} \cdot \mathrm{ka}^{-1}$ corresponds to $10.6 \pm 0.2 \mathrm{MeV} \cdot \mathrm{s}^{-1}$.

\section{GAMMA DOSE RATE RECONSTRUCTION}

Here comes the question of reconstructing gamma dose rate patterns from the series of dose rates measured on the different surfaces exposed during the excavation. The issue of depth distributions of gamma emitting radionuclides has been the subject of several studies in the field of in-situ gamma spectrometry. Mainly three approaches have been proposed: a) the differential attenuation of gamma emission lines as a function of energy, sometimes referred to as the two lines method (Miller et

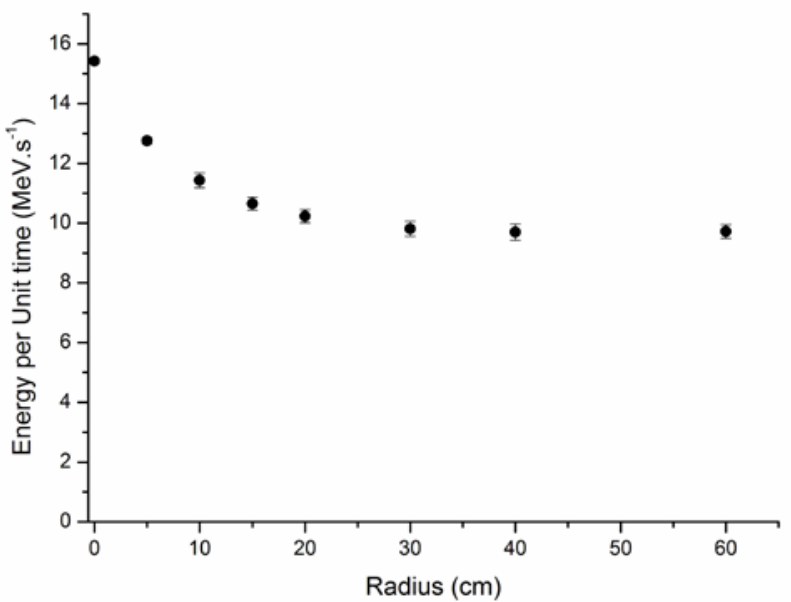

Fig. 3. Attenuated deposited energy above threshold per unit time in a 1.5 inch $\times 1.5$ inch $\mathrm{LaBr}_{3}$ crystal placed on top of calcareous sediment, as a function of the attenuating disk radius. The attenuating disk is made of polymethyl methacrylate and is $4 \mathrm{~cm}$ thick. Error bars correspond to the standard deviation, for energy deposition rates, between the potassium, the uranium and thorium decay chains.

Table 2. Rate of energy deposition above threshold $\left.\left(\mathrm{MeV} \cdot \mathrm{s}^{-1}\right)\right)$ in a $\mathrm{LaBr}_{3}$ cell placed on top of an attenuating disk for various materials and thicknesses. Coefficients are an average of coefficients for potassium, uranium and thorium. For details, see the text and Eq. 2.2.

\begin{tabular}{|c|c|c|c|c|c|}
\hline & & & & 1 & \\
\hline & & $\dot{E}_{0, \text { threshold }}^{\text {attenuated }}$ & & $\overline{\dot{E}}_{0, \text { threshold }}-\dot{E}_{0, \text { threshold }}^{\text {attenuated }}$ & \\
\hline & Thickness (mm) & 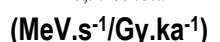 & Std dev. & $\left(G y \cdot k a^{-1 /} / M \cdot s^{-1}\right)$ & Std dev. (\%) \\
\hline & 10 & 12.6 & 0.2 & 350 & 6.6 \\
\hline Aluminum oxide & 20 & 10.7 & 0.2 & 210 & 4.9 \\
\hline & 5 & 11.4 & 0.3 & 246 & 6.8 \\
\hline Brass & 10 & 8.7 & 0.4 & 149 & 5.4 \\
\hline & 1 & 12.3 & 0.5 & 322 & 17.5 \\
\hline Lead & 2 & 10.6 & 0.7 & 208 & 14.0 \\
\hline nomathul mathacrulat & 20 & 12.6 & 0.1 & 355 & 4.1 \\
\hline polymethyl methacrylate & 40 & 10.6 & 0.2 & 209 & 4.1 \\
\hline
\end{tabular}




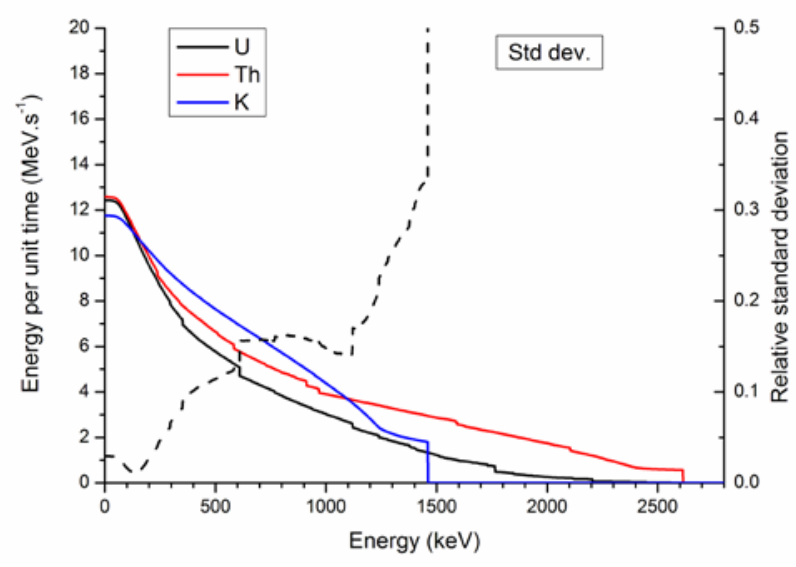

Fig. 4. Simulated cumulative energies recorded by a 1.5 inch $\times 1.5$ inch $\mathrm{LaBr}_{3}$ detector placed on the surface of an infinite calcareous homogeneous sediment, with an attenuating disk of polymethyl methacrylate (radius: $20 \mathrm{~cm}$, thickness: $4 \mathrm{~cm}$ ). Each spectrum has been normalized to a dose-rate of $1 \mathrm{~Gy} \cdot \mathrm{ka}^{-1}$. For clarity the scale is the same as in Fig. 2. At $180 \mathrm{keV}$, the relative standard deviation between the three cumulative energy lines is $1.2 \%$.

al., 1994; Thummerer and Jacob, 1998); b) the forward scattering or photopeak to valley method, based on the ratio of count-rates in the full energy peak of a specific emission line and the count-rate in the valley between the corresponding Compton edge and the photopeak (Zombori et al., 1992; Tyler et al., 1996; Tyler, 1999, 2004; Kastlander and Bargholtz, 2005; Tyler and Copplestone, 2007); c) the use of lead plates and/or collimators (Korun et al., 1994; Benke and Kearfott, 2001). While the application of the two first approaches is limited to simple depth distributions of radioelements - e. g. exponential decrease for ${ }^{137} \mathrm{Cs}$ - the third suffers from the need for repeated measurements and long counting times. Besides it also requires heavy collimators, which is not satisfying when working on sites rich in archaeological material.

The approach presented here takes advantage of the excavation process; a series of measurements performed with a spectrometer cell placed directly above the sediments is proposed, where two spectra are acquired (one with the attenuating disk between the sediments and spectrometer cell, and one without attenuator) every $5 \mathrm{~cm}$ of removed sediments. An excavation is here simulated to outline a way of computing a one-dimensional reconstruction of gamma dose rate pattern along the altitude $(\mathrm{z})$ axis, in a case where the radioelement contents are homogeneous in $(x, y)$ directions. A block of sediments is materialized by 32 siliceous layers (thickness: $5 \mathrm{~cm}$, same composition as for Table 1) on top of each other, for a total height of $160 \mathrm{~cm}$. Two simple case studies will be presented here: in both cases the gamma dose rate varies by a factor of 2 along the measurement profile ( $\mathrm{z}$ axis on Fig. 1), but in the first case - called the 'smoothly heterogeneous' one - the variations in radioelement contents are divided in five steps; in the second case, referred to as the 'strongly heterogeneous' case, the variations occur all at once.

To simulate the excavation process, a series of simulations is performed where the total number of layers is varied, starting with 32 layers (corresponding to a height of 1.60 meters) and ending with 12 layers (only $60 \mathrm{~cm}$ of sediments are remaining: one meter has been removed).

When a dating object (e.g. heated flint, tooth or combustion feature) is found during the excavation process at an altitude $\mathrm{z}$, only half of its environment is remaining, since the sediments lying above have been removed. Therefore the spectrum acquired with the spectrometer placed on top of the sediments at this altitude only characterizes the environment lying underneath the artifact. To overcome this problem, one has to find a way of taking the missing part of the environment into account. A simple way consists of taking the average of the dose rate determined at the altitude $\mathrm{z}$ and the dose rate determined previously at a higher altitude $(z+a)$, which is supposed to characterize the environment that was lying above the artifact and that has been removed by the excavation process. This corresponds to the equation:

$\dot{D}(z)=\frac{\dot{D}_{S}(z)+\dot{D}_{S}(z+a)}{2}$

where $\dot{D}$ stands for the gamma dose rate received by the object to be dated, $\dot{D}_{S}$ the dose rate derived from the gamma spectrum placed above the sediments, and $a$ a distance parameter - to be determined - that would take account of the missing part of the environment.

\section{The 'smoothly heterogeneous' case}

To test the validity of this approach and get a first value of the key parameter $a$, the following configuration was simulated for smooth variations in radioactivity. Two levels were displayed on top of each other: the lower one was made of 18 layers of thickness $5 \mathrm{~cm}$ for a total height of $90 \mathrm{~cm}$ with radioisotopic contents of K: $1 \%, \mathrm{U}: 1 \mathrm{ppm}$ and Th: $6 \mathrm{ppm}$ (concentrations are given in mass fractions), and the uranium series was taken at equilibrium. The upper level consisted in 10 individual layers of thickness $5 \mathrm{~cm}$ with radioelement contents greater by a factor two, i.e. K: $2 \%$, U: 2 ppm, Th: 12 ppm. Between the two levels, four intermediate layers of thickness $5 \mathrm{~cm}$, had contents of layer 1 multiplied respectively by a factor 1.2, 1.4, 1.6 and 1.8. Fig. 5 shows the image of the radioisotopic contents along the profile, as well as the results of Monte Carlo simulations. 'Infinite matrix' dose rates obtained by integrating the energy deposited per unit time in sediment detecting cells (thickness: $1 \mathrm{~cm}$ ) placed every $5 \mathrm{~cm}$ along the profile are displayed as a function of altitude; reconstructed values deduced from the simulated surface gamma spectra recorded by the $\mathrm{LaBr}_{3}$ crystal and computed using Eq. 3.1 are also shown. The value for the parameter $a$ that gives the best reconstructed results, 
compared to the infinite matrix dose rates, is $20 \mathrm{~cm}$ and discrepancies are smaller than $7 \%$.

\section{The 'strongly heterogeneous' case}

In the case of large calcareous blocks present in clayed sediments for instance, the nature of the heterogeneity is significantly different: the radioisotopic contents may strongly vary at the interface between the two elements (limestone and clay). For that matter, a similar case was simulated: the nature of the sediments was not changed - there were two levels of siliceous soil on top of each other - and the proportions of radioelements remained the same, but this time the contents were multiplied by a factor 2 at the interface between the two layers. In this case the bottom level was made of 20 layers $(5 \mathrm{~cm}$ thick) with contents $\mathrm{K}: 1 \%$, U: 1 ppm and Th: $6 \mathrm{ppm}$ and the upper level of 12 layers ( $5 \mathrm{~cm}$ thick) with contents $\mathrm{K}$ : $2 \%$, U: $2 \mathrm{ppm}$ and Th: $12 \mathrm{ppm}$. The variations in the infinite matrix dose rate, as detected by layers of sediments (thickness: $1 \mathrm{~cm}$ as above) were much steeper and Fig. 6 shows reconstructed values. Taking $a$ equal to $20 \mathrm{~cm}$ gives again the best agreement between the two series of dose rates, but in this case, as expected, differences are higher, especially at the level of the interface. However these differences are inferior to $20 \%$.

\section{DISCUSSION}

This series of numerical simulations is meant to try and design a new technique for gamma dosimetry mapping, which offers the advantage of avoiding the drilling of holes in archaeological sites and thus answers expectations from archaeologists, and which could be processed during excavation campaigns.

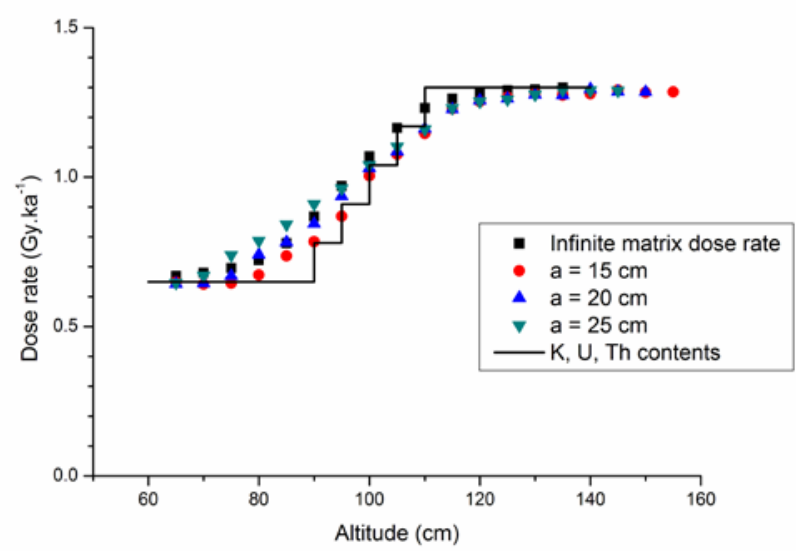

Fig. 5. Dose-rates as a function of altitude in the 'smoothly' heterogeneous case. Radioisotopic contents along the profile have been converted in infinite matrix dose-rates (solid line) and the dose-rate recorded by sediment volume elements are displayed (squares). Three sets of reconstructed values using Eq. 3.1 are plotted for a values equal to $15 \mathrm{~cm}, 20 \mathrm{~cm}$ and $25 \mathrm{~cm}$ (respectively circles, upwards pointing triangles and downwards pointing triangles).
In the field of retrospective dosimetry dating methods, it is common to perform gamma dose rates measurements in $4 \pi$ geometry, either with passive dosimeters or portable gamma spectrometry cells inserted in sediments. The precision of such measurements generally is of a few $\%$ but the number of measurements if often limited; as a result there may be inadequacy between measured gamma dose rates and dose rates received by the objects to be dated.

In comparison, this paper deals with $2 \pi$, or semiinfinite geometry measurements. The first outcome of this paper is a new method for determining gamma dose rates in such geometries, using a subtraction technique involving an attenuator. This technique allows characterizing the radioactivity of a great number of exposed surfaces during excavations processes, since the measurements are quickly performed (in a few minutes) and do not damage the sediments. Consequently, one can take advantage of these numerous determinations for calculating the dose rate really received by the samples which will be dated.

The second question is then to find a way to exploit the $2 \pi$ data for determining the $4 \pi$ gamma dose rates received by the objects to be dated. The model presented here is very simple: it consists of an average of two measurements taken at two different altitudes. Experimental validation will be needed to test and, if necessary, refine this model. It should be noted that in practice, such purely one-dimensional variations do not seem very realistic. Variations in the $(\mathrm{x}, \mathrm{y})$ plane should also occur; for a good coverage of sites, measurements should be performed on each surface in different $(\mathrm{x}, \mathrm{y})$ locations. Therefore a more realistic model would include variations on these axes, and one can expect that taking account of

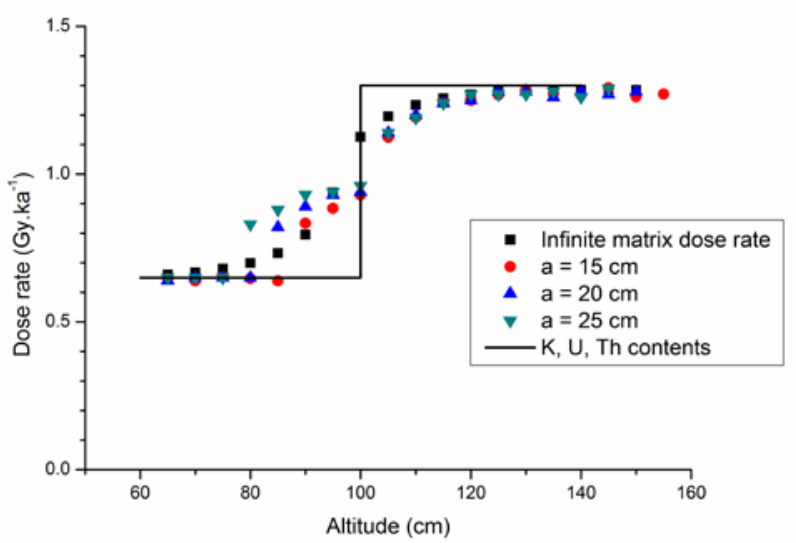

Fig. 6. Dose-rates as a function of altitude in the 'strongly' heterogeneous case. Radioisotopic contents along the profile have been converted in infinite matrix dose-rates (solid line) and the dose-rate recorded by sediment volume elements are displayed (squares). Three sets of reconstructed values using Eq. 3.1 are plotted for a values equal to 15 $\mathrm{cm}, 20 \mathrm{~cm}$ and $25 \mathrm{~cm}$ (respectively circles, upwards pointing triangles and downwards pointing triangles). 
these variations may help reducing the differences between $2 \pi$ reconstructed and $4 \pi$ dose rates. The advantage of the outlined measurement technique lies in the great number of spectra that can be acquired in-situ, allowing a detailed characterization of radioactivity in soils. One can therefore reasonably expect that the use of this technique will improve the accuracy of retrospective dosimetry dating methods, by reducing the inadequacy between measured gamma dose rates and the gamma dose rates of interest.

This being said, problems such as moisture content and radon escape are still not dealt with at this stage. During excavations, the surface of sediments is exposed to open air conditions and this will likely favor some drying and radon leakage from the sediments. To answer such questions would go beyond the scope of the study; however they should be born in mind when applying the technique outlined in this paper.

\section{ACKNOWLEDGEMENTS}

The authors would like to thank Andrew Murray for constructive discussions; the Calculation Centre of the Institut National de Physique Nucléaire et de Physique des Particules for providing important calculation resources; and Prof. David Sanderson and an anonymous reviewer for helpful comments on a previous version of this paper.

\section{REFERENCES}

Agostinelli S, et al. (Geant4 Collaboration), 2003. Geant4 - a simulation toolkit. Nuclear Instruments and Methods A 506: 250-303, DOI 10.1016/S0168-9002(03)01368-8.

Aitken MJ, 1985. Thermoluminescence dating. London, Academic Press: 359pp.

Aitken MJ, Clark PA and Gaffney CF, 1985. Beta and gamma gradients. Nuclear Tracks and Radiation Measurements 10(4-6): 647653, DOI 10.1016/0735-245X(85)90071-7.

Allison J., et al. (Geant4 Collaboration), 2006. Geant4 developments and applications. IEEE Transactions on Nuclear Sciences 53: 270278, DOI 10.1109/TNS.2006.869826.

Allyson JD and Sanderson DCW, 1998. Monte Carlo simulations of environmental airborne gamma-spectrometry. Journal of Environmental Radioactivity 38(3): 259-282, DOI 10.1016/S0265931X(97)00040-4.

Allyson JD and Sanderson DCW, 2001. Spectral deconvolution and operational use of stripping ratios in airborne radiometrics. Journal of Environmental Radioactivity 53(3): 351-363, DOI 10.1016/S0265-931X(00)00141-7.

Aznar MC, Nathan RP. Murray AS and Botter-Jensen L, 2003. Determination of differential dose rates in a mixed beta and gamma field using shielded $\mathrm{Al}_{2} \mathrm{O}_{3}$ : C results of Monte Carlo modelling. Radiation Measurements 37(4-5): 329-334, DOI 10.1016/S13504487(03)00003-9.

Bailiff IK and Slim HA, 2008. Development of reference database for gamma dose assessment in retrospective luminescence dosimetry. Radiation Measurements 43(2-6): 859-863, DOI 10.1016/j.radmeas.2007.12.020.

Bargholz K and Korsbech U, 1997. Conversion of Airborne Gamma Ray Spectra to Ground Level Air Kerma Rates. Radiation Protection Dosimetry 73(1-4): 127-130.
Benke RR and Kearfott KJ, 2001. An improved in situ method for determining depth distributions of gamma-ray emitting radionuclides. Nuclear Instruments and Methods in Physics Research A 463(1-2): 393-412, DOI 10.1016/S0168-9002(01)00449-1.

Brennan BJ, Schwarcz HP and Rink J, 1997. Simulation of the gamma radiation field in lumpy environments. Radiation Measurements 27(2): 299-305, DOI 10.1016/S1350-4487(96)00133-3.

Bucher B, Rybach L and Schwarz G, 2008. Search for long-term radiation trends in the environs of Swiss nuclear power plants. Journal of Environmental Radioactivity 99(8): 1311-1318, DOI 10.1016/j.jenvrad.2008.04.004.

Fain J, Erramli H, Miallier D, Montret M and Sanzelle S, 1985. Environmental gamma dosimetry using TL dosimeters: Efficiency and absorption calculations. Nuclear Tracks and Radiation Measurements 10(4-6): 639-646, DOI 10.1016/0735-245X(85)90070-5.

Guérin G and Mercier N, 2011. Determining gamma dose rates by field gamma spectroscopy in sedimentary media: results of Monte Carlo simulations. Radiation Measurements 46(2): 190-195, DOI 10.1016/j.radmeas.2010.10.003.

Guimarães CC, Moralles M and Okuno E, 2008. Performance of GEANT4 in dosimetry applications: Calculation of X-ray spectra and kerma-to-dose equivalent conversion coefficients. Radiation Measurements 43(9-10): 1525-1531, $\quad$ DOI 10.1016/j.radmeas.2008.07.001.

ICRU, 1994. In situ Gamma-ray Spectrometry in the environment. Report by the International Committee for Radiological Units No. 53.

Kastlander J and Bargholtz C, 2005. Efficient in situ method to determine radionuclide concentration in soil. Nuclear Instruments and Methods in Physics Research A 547(2-3): 400-410, DOI 10.1016/j.nima.2005.03.143.

Korun M, Likar A, Lipoglavsek M, Martincic R and Pucelj B, 1994. In situ measurement of Cs distribution in soil. Nuclear Instruments and Methods in Physics Research B 93(4): 485-491, DOI 10.1016/0168-583X(94)95638-3.

Liritzis Y and Galloway RB, 1980. A new technique for calibrating a $\mathrm{NaI}(\mathrm{Tl})$ scintillometer used to measure gamma dose rates in archaeological sites. Nuclear Instruments and Methods 174(3): 593597, DOI 10.1016/0029-554X(80)91115-5.

Løvborg L and Kirkegaard P, 1974. Response of 3" x 3" NaI(Tl) detectors to terrestrial gamma radiation. Nuclear Instruments and Methods 121(2): 239-251, DOI 10.1016/0029-554X(74)90072-X.

Løvborg L, Bøtter-Jensen L, Kirkegaard P and Christiansen EM, 1979. Monitoring of soil natural radioactivity with portable gamma-ray spectrometer. Nuclear Instruments and Methods 167(2): 341-348, DOI 10.1016/0029-554X(79)90021-1.

Mercier N, Valladas H, Joron J-L, Schiegl S, Bar-Yosef O and Weiner S, 1995. Thermoluminescence dating and the problem of geochemical evolution of sediments. A case study: the Mousterian levels at Hayonim. Israel Journal of Chemistry 35: 137-141.

Mercier N and Falguères C, 2007. Field gamma dose rate measurement with a $\mathrm{NaI}(\mathrm{Tl})$ detector: re-evaluation of the "threshold" technique. Ancient TL 25: 1-4.

Miallier D, Guérin G, Mercier N, Pilleyre T and Sanzelle S, 2009. The Clermont radiometric reference rocks: a convenient tool for dosimetric purposes. Ancient TL 27: 37-44.

Miller KM, Shebell P and Klemic GA, 1994. In situ gamma ray spectrometry for the measurement of uranium in surface soils. Health Physics 67(2): 140-150.

Murray AS, Bowman SGE and Aitken MJ, 1978. Evaluation of the gamma dose rate contribution. PACT 2: 84-96.

Nathan R, Thomas PJ, Murray AS and Rhodes EJ, 2003. Environmental dose rate heterogeneity of beta radiation and its implications for luminescence dating: Monte Carlo modelling and experimental validation. Radiation Measurements 37(4-5): 305-313, DOI 10.1016/S1350-4487(03)00008-8.

Nathan RP and Mauz B, 2008. On the dose rate estimate of carbonaterich sediments for trapped charge dating. Radiation Measurements 43(1): 14-25, DOI 10.1016/j.radmeas.2007.12.012. 
Sanderson DCW and Placido F, 1985. Scottish vitrified forts: background and potential for TL dating. Nuclear Tracks 10(4-6): 799809, DOI 10.1016/0735-245X(85)90093-6.

Thummerer S and Jacob P, 1998. Determination of depth distributions of natural radionuclides with in situ gamma ray spectrometry. $\mathrm{Nu}$ clear Instruments and Methods in Physics Research A 416(1): 161178, DOI 10.1016/S0168-9002(98)00636-6.

Tyler AN, 1999. Monitoring anthropogenic radioactivity in salt marsh environments through in situ gamma ray spectrometry. Journal of Environmental Radioactivity 45(3): 235-252, DOI 10.1016/S0265931X(98)00110-6.

Tyler AN, 2004. High accuracy in situ radiometric mapping. Journal of Environmental Radioactivity 72(1-2): 195-202, DOI 10.1016/S0265-931X(03)00202-9.
Tyler AN, Sanderson DCW and Scott EM, 1996. Estimating and accounting for $137 \mathrm{Cs}$ source burial through in situ gamma spectrometry in salt marsh environments. Journal of Environmental Radioactivity 33(3): 195-212, DOI 10.1016/0265-931X(95)00098-U.

Tyler AN and Copplestone D, 2007. Preliminary results from the first national in situ gamma spectrometry survey of the United Kingdom. Journal of Environmental Radioactivity 17(2-3): 97-106, DOI 10.1016/0265-931X(92)90019-P.

Zombori P, Andrrasi A and Nemeth I, 1992. In situ gamma spectrometric measurements of the contamination in some selected settlements of Byelorussia (BSSR), Ukraine (UkrSSR) and the Russian Federation (RSFSR). Journal of Environmental Radioactivity 96(1-3): 94-102, DOI 10.1016/j.jenvrad.2007.01.029. 